\title{
Platelet-activating Factor Causes Ventilation-Perfusion Mismatch in Humans
}

\author{
Robert Rodriguez-Roisin, ${ }^{*}$ Miquel A. Félez, ${ }^{*}$ K. Fan Chung, Joan A. Barberà, ${ }^{3}$ \\ Peter D. Wagner,' Albert Cobos, ${ }^{\ddagger}$ Peter J. Barnes," and Josep Roca* \\ *Servei de Pneumologia i Al.lèrgia Respiratòria, Hospital Clínic, Facultat de Medicina, Universitat de Barcelona, \\ and ${ }^{\ddagger}$ Unit of Biometry, Medical Department, QF Bayer SA, Barcelona, Spain; ${ }^{\S}$ Department of Thoracic \\ Medicine, National Heart Lung Institute, Royal Brompton Hospital, London, United Kingdom; and 'Department \\ of Medicine, Section of Physiology, University of California at San Diego, La Jolla, California 92093-0623
}

\begin{abstract}
We hypothesized that platelet-activating factor (PAF), a potent inflammatory mediator, could induce gas exchange abnormalities in normal humans. To this end, the effect of aerosolized PAF ( $2 \mathrm{mg} / \mathrm{ml}$ solution; $24 \mu \mathrm{g}$ ) on ventilation-perfusion $\left(\dot{\mathbf{V}}_{\mathrm{A}} / \dot{\mathrm{Q}}\right)$ relationships, hemodynamics, and resistance of the respiratory system was studied in 14 healthy, nonatopic, and nonsmoking individuals ( $23 \pm 1$ [SEM] yr) before and at 2, 4, 6, 8,15 , and 45 min after inhalation, and compared to that of inhaled lyso-PAF in 10 other healthy individuals $(24 \pm 2 \mathrm{yr})$. PAF induced, compared to lyso-PAF, immediate leukopenia $(P$ $<0.001)$ followed by a rebound leukocytosis $(P<0.002)$, increased minute ventilation $(P<0.05)$ and resistance of the respiratory system $(P<0.01)$, and decreased systemic arterial pressure $(P<0.05)$. Similarly, compared to lyso-PAF, $\mathbf{P a}_{\mathrm{O}_{2}}$ showed a trend to fall (by 12.2 $\pm 4.3 \mathrm{mmHg}$, mean \pm SEM maximum change from baseline), and arterial-alveolar $\mathrm{O}_{2}$ gradient increased (by $16.7 \pm 4.3 \mathrm{mmHg})(P<0.02)$ after $P A F$, because of $\dot{V}_{A} / \dot{Q}$ mismatch: the dispersion of pulmonary blood flow and that of ventilation increased by $0.45 \pm 0.1(P<0.01)$ and $0.29 \pm 0.1(P<0.04)$, respectively. We conclude that in normal subjects, inhaled PAF results in considerable immediate $\dot{V}_{A} / \dot{Q}$ inequality and gas exchange impairment. These results reinforce the notion that PAF may play a major role as a mediator of inflammation in the human lung. (J. Clin. Invest. 1994. 93:188-194.) Key words: airway microvascular permeability • asthma • inflammatory mediators • pulmonary gas exchange • pulmonary hemodynamics and mechanics
\end{abstract}

\section{Introduction}

Platelet-activating factor (PAF) ${ }^{1}$ is a potent phospholipid mediator of inflammation with a wide spectrum of activity, includ-

Address correspondence to R. Rodriguez-Roisin, M.D., F.R.C.P. (Edin), Servei de Pneumologia i Al.lèrgia Respiratòria, Hospital Clínic, Villarroel 170, 08036 Barcelona, Spain. 1993.

Received for publication 8 July 1993 and in revised form 17 August

1. Abbreviations used in this paper: $\mathrm{AaPO}_{2}$, alveolar-arterial $\mathrm{O}_{2}$ gradient; ARDS, adult respiratory distress syndrome; DISP R-E*, root mean square difference among measured retentions $(R)$ and excretions (E) of the inert gases (except acetone) corrected for dead space; $f$, respiratory rate; $\mathrm{FEV}_{1}$, forced expiratory volume in the first second; $\mathrm{HR}$, heart rate; $\log \mathrm{SD} \mathrm{Q}$, dispersion of blood flow distribution ( second moment ); $\log \mathrm{SD}$ V, dispersion of ventilation distribution ( second moment); MIGET, multiple inert gas elimination technique; PAF, plate-

J. Clin. Invest.

(c) The American Society for Clinical Investigation, Inc.

0021-9738/94/01/0188/07 \$2.00

Volume 93, January 1994, 188-194 ing chemotaxis and activation of neutrophils and eosinophils $(1,2)$, and induction of both airway and pulmonary microvascular leakage (3-5). When infused into conscious sheep, PAF increases pulmonary vascular resistance, alveolar-arterial $\mathrm{O}_{2}$ gradient $\left(\mathrm{AaPO}_{2}\right)$, and lymph-to-plasma protein concentration ratio $(6,7)$. In humans, inhaled PAF induces bronchoconstriction and an increase in bronchial responsiveness to methacholine associated with a transient neutropenia and with increased number of neutrophils in bronchoalveolar lavage fluid $(8,9)$. However, little is known about the potential effects of inhaled PAF or of other inflammatory mediators on pulmonary gas exchange. By contrast, methacholine, a potent bronchoconstrictor agent, induces considerable bronchoconstriction in patients with mild asthma, but only mild to moderate ventilationperfusion $\left(\dot{\mathrm{V}}_{\mathrm{A}} / \dot{\mathrm{Q}}\right)$ deterioration related to maldistribution of ventilation (10).

Because of these effects of PAF on the pulmonary vasculature and airways (11), we postulated that PAF could disturb gas exchange in normal humans, perhaps mimicking some of the abnormalities naturally observed in patients with bronchial asthma or adult respiratory distress syndrome (ARDS). In asthma, the mechanism of abnormal pulmonary gas exchange is $\dot{\mathrm{V}}_{\mathrm{A}} / \dot{\mathrm{Q}}$ mismatch without shunt, whereas intrapulmonary shunting predominates in ARDS (12).

To test the hypothesis that PAF could induce pulmonary gas exchange abnormalities, we studied the effects of inhaled PAF on pulmonary gas exchange and hemodynamics and compared to those of inhaled lyso-PAF, the biologically inactive PAF precursor and metabolite, in a group of healthy young volunteers.

\section{Methods}

Individuals. 24 healthy individuals ( 21 males and 3 females, ages 18$36 \mathrm{yr}$ ) were recruited from the community for the study, which was approved by our center's Research Committee on Human Investigations. All subjects gave written informed consent after the purpose, risks, and potential of the study were explained and understood. Anthropometric, white blood cell, and baseline functional data appear in Table I. All were nonsmokers and nonatopic as judged by one or more wheal-and-flare responses to skin prick tests with common allergen extracts. All subjects were free of respiratory infection for $\geq 6 \mathrm{wk}$ preceding the study. They demonstrated normal spirometry (values $>80 \%$ predicted) and a negative abbreviated methacholine bronchial challenge.

Procedures. Blood samples were collected anaerobically through catheters inserted into the radial and pulmonary arteries. Arterial and mixed venous $\mathrm{O}_{2}$ pressure, $\mathrm{CO}_{2}$ pressure, and $\mathrm{pH}$ were analyzed in duplicate using standard electrodes (IL 1302; Instrumentation Labora-

let-activating factor; $\mathrm{Pa}_{\mathrm{O}_{2}}$, partial $\mathrm{O}_{2}$ pressure in arterial blood; PAP, pulmonary arterial pressure; $\dot{\mathrm{Q}}_{\mathrm{T}}$, cardiac output; Rrs, respiratory system resistance; RSS, remaining sum of squares; $\dot{\mathrm{V}}_{\mathrm{E}}$, minute ventilation; $\dot{\mathrm{VO}}_{2}, \mathrm{O}_{2}$ uptake. 
Table I. Anthropometric, White Blood Cell, and Baseline Functional Data (Mean \pm SEM) on Entry of the Study

\begin{tabular}{|c|c|c|}
\hline & PAF & Lyso-PAF \\
\hline$n$ & 14 & 10 \\
\hline Gender (male/female) & $12: 2$ & $9: 1$ \\
\hline Age $(y r)$ & $23 \pm 1$ & $24 \pm 2$ \\
\hline Height $(\mathrm{cm})$ & $173 \pm 2$ & $176 \pm 3$ \\
\hline Weight $(\mathrm{kg})$ & $70 \pm 2$ & $76 \pm 4$ \\
\hline Leukocytes $\left(\times 10^{9} /\right.$ liter $)$ & $5.9 \pm 0.3$ & $8.3 \pm 0.8^{*}$ \\
\hline $\mathrm{FEV}_{1}$ (liter) & $4.3 \pm 0.2$ & $4.6 \pm 0.2$ \\
\hline (\% pred) & $103 \pm 3$ & $106 \pm 3$ \\
\hline FVC (liter) & $5.2 \pm 0.2$ & $5.6 \pm 0.2$ \\
\hline (\% pred) & $103 \pm 3$ & $104 \pm 3$ \\
\hline $\mathrm{FEV}_{1} / \mathrm{FVC}(\%)$ & $82.6 \pm 1.8$ & $83.3 \pm 2.5$ \\
\hline $\mathrm{Pa}_{\mathrm{O}_{2}}(\mathrm{mmHg})$ & $103.4 \pm 1.2^{\ddagger}$ & $103.7 \pm 2.0$ \\
\hline $\mathrm{Pa}_{\mathrm{CO}_{2}}(\mathrm{mmHg})$ & $38.4 \pm 0.6^{\ddagger}$ & $38.5 \pm 0.8$ \\
\hline $\mathrm{AaPO}_{2}(\mathrm{mmHg})$ & $4.9 \pm 0.9^{\ddagger}$ & $4.0 \pm 1.4$ \\
\hline $\mathrm{P} \overline{\mathrm{v}} \mathrm{O}_{2}(\mathrm{mmHg})$ & $41.6 \pm 0.5^{\ddagger}$ & $43.3 \pm 1.2$ \\
\hline
\end{tabular}

FVC, forced vital capacity. Predicted equations for spirometry are those of Roca et al. (13). ${ }^{*} P<0.05$ (Mann-Whitney's test). $\left({ }^{\ddagger} n=13\right.$ ). pred, predicted; $\mathrm{P}_{\bar{v}}{ }_{2}$, mixed venous $\mathrm{O}_{2}$ pressure in blood.

tories, Milano, Italy). Hemoglobin concentration was measured by a co-oximeter (IL 482; Instrumentation Laboratories). A low dead space, low resistance, and nonrebreathing valve (model no. 1500; Rudolph Instruments, Kansas City, MO) connected to a heated metal mixing chamber was used to collect the mixed expired gas. Oxygen uptake $\left(\mathrm{V}_{2}\right)$ and $\mathrm{CO}_{2}$ production were calculated from mixed expired $\mathrm{O}_{2}$ and $\mathrm{CO}_{2}$ concentrations measured by mass spectrometry (multigas monitor MS2; BOC-Medishield, London, United Kingdom). Minute ventilation $\left(\dot{\mathrm{V}}_{\mathrm{E}}\right)$ and respiratory rate $(\mathrm{f})$ were measured using a calibrated Wright spirometer (Respirometer MK8; BOC-Medical, Essex, United Kingdom). The alveolar-arterial $\mathrm{O}_{2}$ gradient $\left(\mathrm{AaPO}_{2}\right)$ was calculated according to the alveolar gas equation using the measured respiratory exchange ratio.

Total respiratory system resistance (Rrs) was measured by forced oscillation applied at the mouth, its analysis being restricted to frequencies between 6 and $10 \mathrm{~Hz}$. Details of the measurement of Rrs in our laboratory are reported in reference 10 .

A three-lead electrocardiogram, heart rate (HR), and systemic (Ps) as well as pulmonary arterial (PAP) pressures (using a Swan-Ganz catheter) were continuously recorded throughout the whole study (HP 7830A monitor and HP 7754B recorder; Hewlett-Packard, Waltham, MA). Cardiac output ( $\left.\dot{Q}_{\mathrm{T}}\right)$ was calculated according to the Fick principle using the measured $\dot{\mathrm{V}}_{2}$ and the calculated $\mathrm{O}_{2}$ contents of arterial and mixed venous blood. $\dot{\mathrm{V}}_{\mathrm{A}} / \dot{\mathrm{Q}}$ distributions were estimated by the multiple inert gas elimination technique (MIGET) (14), the inert gases being dissolved in normal saline and infused through a peripheral venous cannula. Specific features of this technique in our laboratory have been reported earlier $(15,16)$. Ventilation-perfusion distributions were estimated from inert gas data using a least square algorithm with enforced smoothing (17). The duplicate samples of each set of measurements (at baseline, and at 8,15 , and $45 \mathrm{~min}$ after each challenge, only; see below) were treated separately, resulting in two $\dot{\mathrm{V}}_{\mathrm{A}} / \dot{\mathrm{Q}}$ distributions at each time point, the final data being the average of variables determined from both distributions at each time.

Arterial and mixed venous blood were taken for measurement of circulating blood cells. Total white blood cell and differential cell counts were performed (H.1 ${ }^{\mathrm{T}}$ M System; Technicon, Tarytown, NY).

Design of the study. All studies were performed with individuals breathing room air and seated in an armchair. Once all the hemodynamic and respiratory parameters were stable and the inert gas solution had been infused for $\geq 45 \mathrm{~min}$ to allow for the establishment of ade- quate steady-state conditions ( see below), baseline measurements were performed. 14 subjects were then challenged with $\operatorname{PAF}\left(\mathrm{C}_{16}\right)(1-0$-hexadecyl-2-acetyl-sn-glycero-3-phosphocholine, fully saturated; Novabiochem AG, Laufelfingen, Switzerland). PAF was kept as stock solution of $10 \mathrm{mg} / \mathrm{ml}$ in ethanol at $-80^{\circ} \mathrm{C}$. Solutions of $2 \mathrm{mg} / \mathrm{ml}$ in $0.35 \%$ bovine serum albumin were freshly prepared on each study day. Details of the PAF challenge performed in our laboratory have been reported elsewhere $(18,19)$. PAF was delivered from a nebulizer attached to a dosimeter (Morgan Nebichek, PK Morgan, Chatham, Kent, United Kingdom), driven by compressed air at a pressure of $22 \mathrm{lb} /$ in $^{2}(152$ $\mathrm{kPa})$. The output of the nebulizer was $6 \mu \mathrm{l} /$ breath. We administered two breaths of PAF $(24 \mu \mathrm{g})$, subjects inhaling from functional residual capacity to total lung capacity over a period of $5 \mathrm{~s}$ followed by a 10-s breathhold for each.

Because the time course of gas exchange response to PAF was unknown, we took single measurements $2 \mathrm{~min}$ apart during the first $6 \mathrm{~min}$ after challenge (at 2, 4, and $6 \mathrm{~min}$ ), and then duplicate measurements at 8,15 , and $45 \mathrm{~min}$. In 8 out of the 14 subjects, all sets of measurements consisted of the following steps in sequence: $(a)$ inert gas sampling and recording of $\dot{\mathrm{V}}_{\mathrm{E}}$ and $\mathrm{f},(b)$ respiratory gas sampling, (c) systemic and pulmonary hemodynamic recordings (available at all time points in two of the eight individuals only), and $(d)$ sampling for circulating blood cells. In the other six individuals, to better evaluate pulmonary artery pressures, identical sets of measurements without inert gas sampling were carried out. Likewise, in the latter six subjects, measurements of Rrs only were performed 1 wk later following identical time course, as the circuit for sampling expired respiratory and inert gases is not suitable for Rrs measurements.

Identical procedures and study design were followed with lyso-PAF $\left(C_{16}\right)$ (1-0-hexadecyl-sn-glycero-3-phosphocholine, fully saturated; Novabiochem AG) challenge (two breaths, $24 \mu \mathrm{g}$ ) in 10 other individuals. All these subjects had a complete sets of measurements as after PAF, including measurements of pulmonary artery pressures; in addition, seven only had measurements of Rrs 1 wk later using identical protocol. Except for total white cell counts, no differences were observed in any of the parameters at baseline between the participants who received PAF or lyso-PAF (Tables I-III).

Maintenance of steady-state conditions after the PAF and lyso-PAF challenges was demonstrated by stability $( \pm 5 \%)$ of hemodynamic (HR and Ps) and spirometric ( f and tidal volume) variables, and by the close agreement between duplicate measurements of mixed expired and arterial respiratory gases (within $\pm 5 \%$ ). These conditions were reached in all but one participant in whom respiratory gases only were measured after PAF. The reliability of the inert gas data is indicated by the remaining sum of squares (RSS) between the measured data and the least squares fit (by the smoothing algorithm [17]). We found that the distribution of RSS was within expected levels for a set of six randomly distributed error terms with unit variance at all time points. The mean RSS at each time point was $6.5 \pm 0.9$ (baseline), $6.1 \pm 2.0(2 \mathrm{~min})$, $6.3 \pm 1.4(4 \mathrm{~min}), 3.9 \pm 0.7(6 \mathrm{~min}), 4.7 \pm 0.7(8 \mathrm{~min}), 3.8 \pm 0.5$ (15 $\mathrm{min})$, and $5.6 \pm 1.0(45 \mathrm{~min}) .94 \%$ of RSS were $\leq 15.0,86 \%$ were $\leq 10.0$, and $59 \% \leq 5.0$, and the mean RSS was $5.3 \pm 0.3$ ( 150 sets of data obtained). The chi square distribution predicts $97 \%$ to be $<15.0$, $90 \%$ to be $<10.0$, and $55 \%$ to be $<5.0(20)$.

Safety precautions. Individuals were instructed that the study could be immediately terminated should unusual symptoms other than flushing and coughing develop, but this was never required. Three physicians were present at all times, with one devoted exclusively to the observation of subjects.

Statistical analysis. Data are reported as mean \pm SEM. Because the time course of changes after PAF clearly showed an initial response, some plateauing and then return toward baseline conditions, a conventional analysis of variance to determine significance of PAF effects was considered inappropriate. Accordingly, the maximum change from baseline for each outcome variable was considered a suitable summary measure of its individual response profile (21). This considers the individual as the basic unit and uses the responses for each subject to construct a single number that summarizes some aspect of that individual's response curve. We chose the maximum change from baseline, which 


\begin{tabular}{|c|c|c|c|c|c|c|c|c|c|}
\hline & & \multirow[b]{2}{*}{ Baseline } & \multicolumn{6}{|c|}{ After challenge } & \multirow[b]{2}{*}{$P$} \\
\hline & & & $2 \min$ & $4 \min$ & $6 \mathrm{~min}$ & $8 \mathrm{~min}$ & $15 \mathrm{~min}$ & $45 \mathrm{~min}$ & \\
\hline \multirow[t]{2}{*}{$\mathrm{Pa}_{\mathrm{O}_{2}}(\mathrm{mmHg})$} & PAF & $103.4 \pm 1.2$ & $95.4 \pm 4.7$ & $93.6 \pm 4.5$ & $94.5 \pm 4.4$ & $95.2 \pm 4.5$ & $97.1 \pm 4.2$ & $101.3 \pm 1.5$ & $<0.09$ \\
\hline & Lyso-PAF & $103.7 \pm 2.0$ & $101.0 \pm 3.2$ & $102.3 \pm 2.2$ & $102.4 \pm 1.9$ & $102.8 \pm 1.6$ & $101.8 \pm 1.1$ & $103.8 \pm 2.4$ & \\
\hline \multirow[t]{2}{*}{$\mathrm{AaPO}_{2}(\mathrm{mmHg})$} & PAF & $4.9 \pm 0.9$ & $16.4 \pm 4.2$ & $19.6 \pm 3.9$ & $18.5 \pm 3.7$ & $15.5 \pm 3.8$ & $13.6 \pm 2.9$ & $8.9 \pm 1.2$ & $<0.02$ \\
\hline & Lyso-PAF & $4.0 \pm 1.4$ & $5.3 \pm 1.7$ & $4.9 \pm 1.7$ & $4.9 \pm 1.5$ & $5.3 \pm 1.6$ & $4.2 \pm 1.1$ & $4.8 \pm 1.4$ & \\
\hline \multirow[t]{2}{*}{$\mathrm{P} \overline{\mathrm{v}} \mathrm{O}_{2}(\mathrm{mmHg})$} & PAF & $41.6 \pm 0.5$ & $42.1 \pm 1.0$ & $40.0 \pm 1.0$ & $39.2 \pm 0.7$ & $39.5 \pm 0.7$ & $39.6 \pm 0.8$ & $39.4 \pm 0.8$ & $=0.05$ \\
\hline & Lyso-PAF & $43.3 \pm 1.2$ & $42.9 \pm 1.2$ & $42.2 \pm 1.0$ & $42.2 \pm 1.0$ & $42.4 \pm 0.9$ & $42.4 \pm 1.0$ & $41.6 \pm 1.1$ & \\
\hline \multirow[t]{2}{*}{$\log$ SD Q } & PAF & $0.36 \pm 0.1$ & $0.69 \pm 0.1$ & $0.73 \pm 0.1$ & $0.75 \pm 0.1$ & $0.75 \pm 0.1$ & $0.64 \pm 0.1$ & $0.44 \pm 0.1$ & $<0.01$ \\
\hline & Lyso-PAF & $0.36 \pm 0.1$ & $0.38 \pm 0.1$ & $0.37 \pm 0.1$ & $0.36 \pm 0.1$ & $0.37 \pm 0.1$ & $0.41 \pm 0.1$ & $0.38 \pm 0.1$ & \\
\hline \multirow[t]{2}{*}{$\log S D V$} & PAF & $0.37 \pm 0.1$ & $0.60 \pm 0.1$ & $0.61 \pm 0.1$ & $0.56 \pm 0.1$ & $0.55 \pm 0.1$ & $0.51 \pm 0.1$ & $0.43 \pm 0.1$ & $<0.04$ \\
\hline & Lyso-PAF & $0.40 \pm 0.1$ & $0.43 \pm 0.1$ & $0.38 \pm 0.1$ & $0.43 \pm 0.1$ & $0.40 \pm 0.1$ & $0.43 \pm 0.1$ & $0.40 \pm 0.1$ & \\
\hline \multirow[t]{2}{*}{ DISP R-E* } & PAF & $2.2 \pm 0.4$ & $6.4 \pm 1.8$ & $6.6 \pm 1.5$ & $5.9 \pm 1.3$ & $5.7 \pm 1.3$ & $4.8 \pm 1.2$ & $3.1 \pm 0.5$ & $<0.03$ \\
\hline & Lyso-PAF & $2.2 \pm 0.3$ & $2.3 \pm 0.3$ & $2.3 \pm 0.4$ & $2.3 \pm 0.3$ & $2.2 \pm 0.5$ & $3.0 \pm 0.8$ & $2.5 \pm 0.6$ & \\
\hline
\end{tabular}

$P$ refers to differences between the maximum changes from baseline after PAF and Lyso-PAF challenges, using Mann-Whitney's test.

may be interpreted as a measure of the maximum effect of PAF. Since distributions of these summary measures clearly showed skewness, these maximum changes from baseline after PAF and lyso-PAF challenges were treated as raw data and compared using common nonparametric methods (Mann-Whitney's test). Spearman's correlations were used to assess the relationships between variables. Wilcoxon's test was used to compare paired arterial and mixed venous white cell counts within each group. Significance was set at $P \leq 0.05$ in all instances.

\section{Results}

Clinical data. All but one subject receiving PAF ( 19 out of 20 challenges) noticed facial flushing, and coughing occurred in seven; no other symptoms developed. By contrast, lyso-PAF inhalation did not cause any symptoms.

Circulating white blood cells. Compared to lyso-PAF (from $8.3 \pm 0.8$ to $8.0 \pm 0.8 \times 10^{9} /$ liter, total white cell count in mixed venous blood decreased transiently (from $5.9 \pm 0.3$ to $3.5 \pm 0.3$ $\times 10^{9} /$ liter $)(P<0.001)$ within 4 min after PAF inhalation followed by a rebound leukocytosis at $8 \mathrm{~min}\left(8.6 \pm 0.5 \times 10^{9} /\right.$ liter, which persisted at $15 \mathrm{~min}\left(10.0 \pm 0.8 \times 10^{9} /\right.$ liter $)$ and at $45 \mathrm{~min}\left(9.6 \pm 0.6 \times 10^{9} /\right.$ liter $)(P<0.002)$, as noted previously (18). The fall of total white cell count accounted for an early ( 4 min) reduction (from $4.0 \pm 0.3$ to $2.0 \pm 0.3 \times 10^{9} /$ liter $)(P$ $<0.001$ ) in circulating mixed venous blood neutrophils and a rebound neutrophilia at 8,15 , and $45 \mathrm{~min}$ (to $6.5 \pm 0.4$, $7.9 \pm 0.8$, and $7.8 \pm 0.6 \times 10^{9} /$ liter, respectively $)(P<0.002)$.
Except at 4 min after PAF, no overall significant differences were observed between arterial and mixed venous white cell counts; at that time point, however, both arterial leukopenia $\left(3.0 \pm 0.4 \times 10^{9} /\right.$ liter $)(P<0.007)$ and neutropenia $(1.5 \pm 0.4$ $\times 10^{9}$ /liter $)(P<0.004)$ were more pronounced.

Respiratory and inert gas responses (Table III and Figs. 1-3). As expected, baseline $\mathrm{Pa}_{\mathrm{O}_{2}}, \mathrm{~Pa}_{\mathrm{CO}_{2}}$ (PAF, 38.4 \pm 0.6 vs lyso-PAF, $38.5 \pm 0.8 \mathrm{mmHg}$ ), $\mathrm{AaPO}_{2}$, arterial pH (PAF, $7.41 \pm 0.01$ vs. $7.39 \pm 0.01, \mathrm{PV}_{2}$ and $\dot{\mathrm{Vo}}_{2}$ (PAF, $250 \pm 16$ vs lysoPAF, $312 \pm 32 \mathrm{ml} / \mathrm{min}$ ) were within normal limits and not different between the subjects who received PAF or those who received lyso-PAF (Table II). Compared to lyso-PAF, $\mathrm{Pa}_{\mathrm{O}_{2}}$ showed a trend to fall by $12.3 \pm 4.3$ (mean \pm SEM maximum change from baseline) after PAF $(P<0.09)$, and returned towards baseline values at $45 \mathrm{~min}$. Thus, there was a significant (threefold) immediate increase in $\mathrm{AaPO}_{2}$ (by 16.7 \pm 4.3 $\mathrm{mmHg})(P<0.02)$, which fell towards baseline values at 45 min. Similarly, $\mathrm{P}_{\overline{\mathrm{v}}} \mathrm{O}_{2}$ decreased initially by $3.9 \pm 0.6 \mathrm{mmHg}(P$ $=0.05$ ). Fig. 1 illustrates the individual time courses of $\mathrm{AaPO}_{2}$, in which it is shown that six participants were highly responsive, two were mildly responsive, and five failed to respond to PAF, and Fig. 2 depicts the mean \pm SEM maximum changes from baseline of $\mathrm{AaPO}_{2}$, after PAF and lyso-PAF challenges. There were no significant differences in the baseline data for those six subjects who were high responders. By contrast, $\mathrm{Pa}_{\mathrm{CO}_{2}}, \mathrm{pH}$, and $\dot{\mathrm{V}}_{2}$ remained essentially stable without significant differences between PAF and lyso-PAF challenges.

Table III. Ventilatory, Lung Mechanic, and Hemodynamic Responses to PAF and Lyso-PAF Challenges (Mean \pm SEM)

\begin{tabular}{|c|c|c|c|c|c|c|c|c|c|}
\hline & & \multirow[b]{2}{*}{ Baseline } & \multicolumn{6}{|c|}{ After challenge } & \multirow[b]{2}{*}{$P$} \\
\hline & & & $2 \mathrm{~min}$ & $4 \mathrm{~min}$ & $6 \mathrm{~min}$ & $8 \mathrm{~min}$ & $15 \mathrm{~min}$ & $45 \mathrm{~min}$ & \\
\hline \multirow[t]{2}{*}{$\dot{\mathrm{V}}_{\mathbf{E}}($ liter/min $)$} & PAF & $7.8 \pm 0.5$ & $9.9 \pm 1.0$ & $10.2 \pm 1.0$ & $10.4 \pm 1.0$ & $10.2 \pm 1.0$ & $10.2 \pm 1.0$ & $8.7 \pm 0.3$ & $<0.05$ \\
\hline & Lyso-PAF & $8.5 \pm 0.8$ & $9.2 \pm 0.7$ & $8.8 \pm 0.7$ & $8.8 \pm 0.8$ & $8.6 \pm 0.6$ & $9.1 \pm 0.7$ & $8.9 \pm 0.7$ & \\
\hline \multirow[t]{2}{*}{$\operatorname{Rrs}\left(\mathrm{cm} \mathrm{H}_{2} \mathrm{O} \cdot\right.$ liter $\left.^{-1} \cdot \mathrm{s}\right)$} & PAF & $2.78 \pm 0.2$ & $3.59 \pm 0.3$ & $3.65 \pm 0.4$ & $3.30 \pm 0.3$ & $3.27 \pm 0.2$ & $3.12 \pm 02$ & $2.98 \pm 0.2$ & $<0.02$ \\
\hline & Lyso-PAF & $2.58 \pm 0.3$ & $2.49 \pm 0.3$ & $2.55 \pm 0.2$ & $2.56 \pm 0.2$ & $2.40 \pm 0.2$ & $2.32 \pm 0.2$ & $2.38 \pm 0.2$ & \\
\hline \multirow[t]{2}{*}{$\overline{\mathrm{Ps}}(\mathrm{mmHg})$} & PAF & $85.5 \pm 3.2$ & $83.0 \pm 3.9$ & $77.8 \pm 3.5$ & $75.2 \pm 3.6$ & $80.8 \pm 3.0$ & $81.7 \pm 2.8$ & $80.9 \pm 2.1$ & $<0.05$ \\
\hline & Lyso-PAF & $88.8 \pm 2.0$ & $91.6 \pm 2.9$ & $91.0 \pm 2.4$ & $89.8 \pm 3.3$ & $88.6 \pm 4.9$ & $94.4 \pm 4.0$ & $89.0 \pm 3.9$ & \\
\hline
\end{tabular}

$P$ refers to differences between the maximum changes from baseline after PAF and lyso-PAF challenges, using Mann-Whitney's test. 
Alveolar-Arterial $\mathrm{PO}_{2}$ Difference
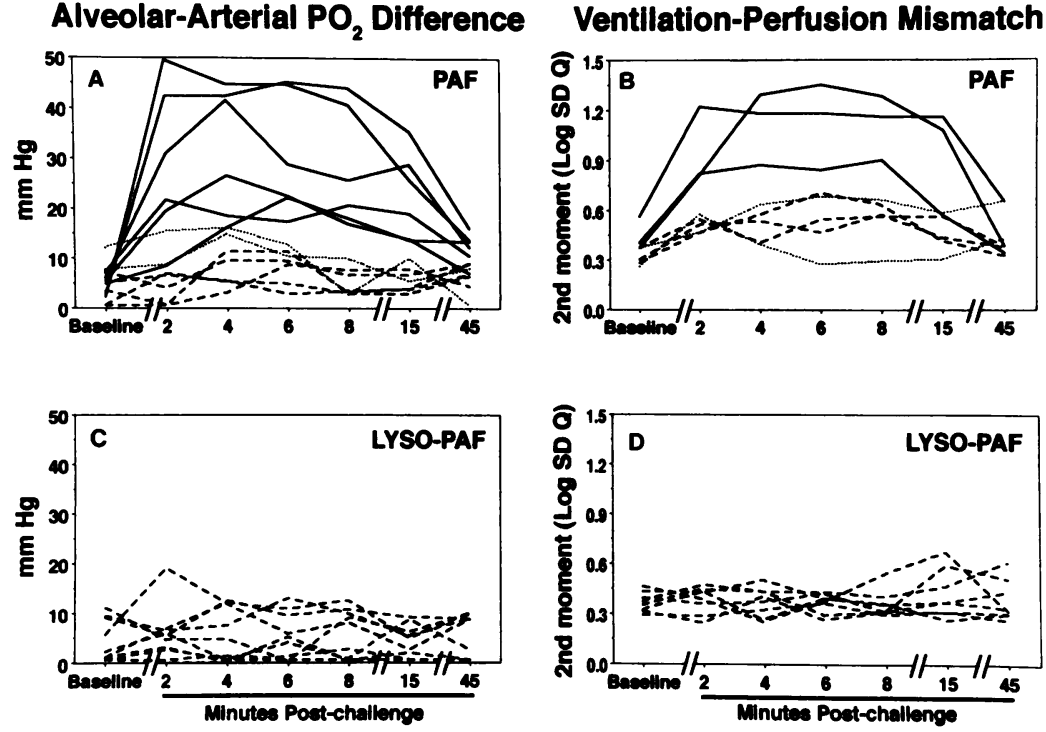

Figure 1. Individual time courses of the alveolar-arterial $\mathrm{PO}_{2}$ difference and the dispersion of pulmonary blood flow ( $\log S D Q$ ) (in their respective units) after $\mathrm{PAF}$ and lyso-PAF. After inhalation of PAF, $\mathrm{AaPO}_{2}$ values $(A)$ immediately increased in six individuals, to persist thereafter and to approach baseline values by $45 \mathrm{~min}$ (solid lines, high responders), two others showed slight increases (dotted lines, mild responders), and the five remainders did not respond (dashed lines, nonresponders). The values of the latter seven subjects were essentially less than the mean $+2 \mathrm{SD}$ ( $12.3 \mathrm{mmHg}$ ) of the mean values of $\mathrm{AaPO}_{2}$ at all time points after lyso-PAF of each individual (dashed lines, $C$ and $D$ ). The profiles of the individual time courses of $\log$ SD $Q$ changes after PAF challenge (B) were similar to those of $\mathrm{AaPO}_{2}$, as shown by identical line type. No changes were shown after lysoPAF.
Baseline $\dot{\mathrm{V}}_{\mathrm{A}} / \mathrm{Q}$ ratio distributions were narrow and unimodal in all subjects, in agreement with previous inert gas studies in healthy individuals (22-24). After PAF the distribution of pulmonary blood flow and that of alveolar ventilation broad-
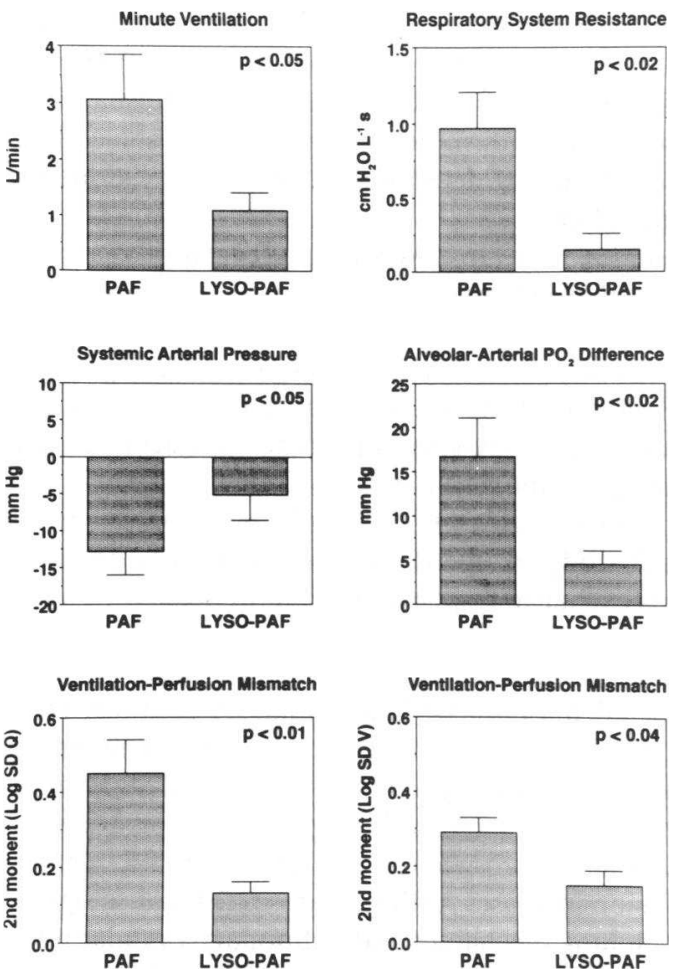

Figure 2. Mean \pm SEM maximum changes from baseline (in their respective units) after PAF and lyso-PAF of minute ventilation, respiratory system resistance, systemic arterial pressure, alveolar-arterial $\mathrm{PO}_{2}$ difference, and $\dot{\mathrm{V}}_{\mathrm{A}} / \mathrm{Q}$ distributions (dispersion indices, $\log \mathrm{SD}$ $\mathrm{Q}$ and $\log \mathrm{SD} \mathrm{V}$ ). Note that the changes after PAF in the first three parameters were modest compared to those of the three indices of gas exchange. Minute ventilation and respiratory system resistance increased by 39 and $35 \%$, respectively, and systemic arterial arterial pressure decreased by $15 \%$. These changes contrast with the remarkable increases in the alveolar-arterial $\mathrm{PO}_{2}$ difference (by $341 \%$ ), log SD Q (by $125 \%$ ), and $\log$ SD V (by $78 \%$ ). ened in all subjects, and in three bimodal blood flow distribution profiles with distinct low $\dot{\mathrm{V}}_{\mathrm{A}} / \mathrm{Q}$ regions were observed between 2 and $15 \mathrm{~min}$. Distributions returned essentially to normal at $45 \mathrm{~min}$. We quantify the dispersion of pulmonary perfusion $(\log S D Q)$ and that of alveolar ventilation $(\log S D$ $\mathrm{V}$ ), as the second moment of the $\dot{\mathrm{V}}_{\mathrm{A}} / \dot{\mathrm{Q}}$ distributions about their mean on a log scale (normal range $=0.3-0.6[25]$ ), and also by an overall index of $\dot{\mathrm{V}}_{\mathrm{A}} / \dot{\mathrm{Q}}$ heterogeneity of lung function (DISP R-E*, i.e., the combined dispersion of both blood flow and ventilation distributions corrected for dead space) (normal values $<3.0$ [22]). All of these indices of $\dot{V}_{A} / \dot{Q}$ inequality increased (worsened) (by $0.45 \pm 0.1[P<0.01$ )], by $0.29 \pm 0.1[P<0.04]$, and by $5.1 \pm 1.2[P<0.03]$, respectively) after PAF inhalation (Table II; Fig. 2), in some cases to considerably abnormal values (Fig. 1) during the above time sequence. Fig. 1 shows the individual time courses of $\log \mathrm{SD} Q$ values and Fig. 2 illustrates mean $\pm S E M$ maximum changes from baseline of $\log$ SD Q and $\log$ SD V, after PAF and lysoPAF challenges. Shunt (trivial at baseline) and dead space expressed as milliliters per breath (PAF, $117 \pm 16$ vs lyso-PAF, $144 \pm 11)$ did not show any significant effect after PAF. Likewise, the first moments of the $\dot{\mathrm{V}}_{\mathrm{A}} / \mathrm{Q}$ distributions (the mean $\dot{\mathrm{V}}_{\mathrm{A}} / \mathrm{Q}$ ratios of the blood flow $(\overline{\mathrm{Q}})$ (PAF, $0.87 \pm 0.1$ vs lysoPAF, $0.83 \pm 0.1$ ) and that of ventilation distributions ( $\bar{v})$ (PAF, $1.04 \pm 0.1$ vs lyso-PAF, $0.97 \pm 0.1)$ did not change after PAF.

No significant differences $(P=0.78)$ were shown between predicted $\mathrm{Pa}_{\mathrm{O}_{2}}$ ( reflecting the amount of $\dot{\mathrm{V}}_{\mathrm{A}} / \dot{\mathrm{Q}}$ mismatch computed by MIGET) and measured $\mathrm{Pa}_{\mathrm{O}_{2}}$ throughout the period of study after PAF, suggesting that other potential mechanisms of hypoxemia, such as diffusion limitation for $\mathrm{O}_{2}$, increased intrapulmonary parenchymal $\mathrm{V}_{2}$ or increased postpulmonary shunt (bronchial and Thebesian circulations), were not present (23).

Indices of respiratory gas exchange and those of $\dot{\mathrm{V}}_{\mathrm{A}} / \dot{\mathrm{Q}}$ mismatch described above correlated closely: $\mathrm{Pa}_{\mathrm{O}_{2}}$ and $\mathrm{AaPO}_{2}$ correlated with $\log \mathrm{SD} \mathrm{Q}(r,-0.86$, and 0.87$), \log \mathrm{SD} \mathrm{V}(r$, -0.75 , and 0.68$)$, and DISP R-E* $(r,-0.89$, and 0.87$)(P$ $<0.05$, each $)$, respectively. The $\dot{\mathrm{V}}_{\mathrm{A}} / \dot{\mathrm{Q}}$ distributions of one of the three subjects with a bimodal pattern are illustrated in Fig. 3. As shown, immediately after challenge the blood flow distribution was clearly bimodal with abnormally low $\dot{\mathrm{V}}_{\mathrm{A}} / \dot{\mathrm{Q}}$ areas now present and accounting for $53 \%$ of total pulmonary blood 

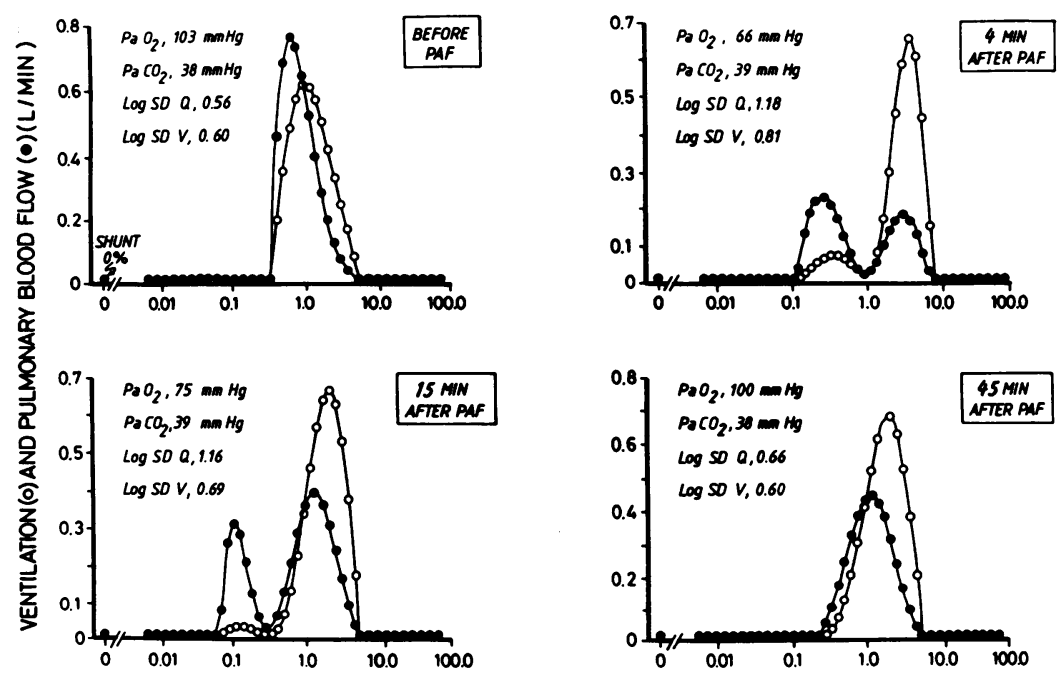

Figure 3. Representative sequence of $\dot{\mathrm{V}}_{\mathrm{A}} / \mathrm{Q}$ distributions in one individual challenged with PAF. At 4 min after challenge, $\mathrm{Pa}_{\mathrm{O}_{2}}$ fell and there was moderate to severe $\dot{\mathrm{V}}_{\mathrm{A}} / \mathrm{Q}$ mismatch, as shown by marked increases in the dispersion of blood flow $(\log$ SD $Q)$ and that of ventilation $(\log S D \mathrm{~V})$. Note that immediately after PAF blood flow distribution was clearly bimodal. At $15 \mathrm{~min}$, these functional findings were still present but, by $45 \mathrm{~min}$, all variables returned to or towards

VAIQ RATIO baseline values.

flow. This markedly altered pulmonary gas exchange and resulted in considerable hypoxemia, still present at $15 \mathrm{~min}$. However, gas exchange indices reverted towards baseline values by $45 \mathrm{~min}$.

Ventilatory, lung mechanic, and hemodynamic responses (Table III and Fig. 2). PAF and lyso-PAF both had no effects on respiratory frequency (PAF, $14 \pm 0.6$ vs lyso-PAF, $14 \pm 1.0$ $\mathrm{min}^{-1}$ ) or tidal volume (PAF, $0.58 \pm 0.1$ vs lyso-PAF, $0.63 \pm 0.1$ liter/min), but there was a small effect of PAF on minute ventilation (increase by $3.1 \pm 0.8 \mathrm{liter} / \mathrm{min})(P<0.05)$, with return to baseline levels at $45 \mathrm{~min}$. Likewise, Rrs slightly increased (by $0.97 \pm 0.2 \mathrm{~cm} \mathrm{H}_{2} \mathrm{O} \cdot \operatorname{liter}^{-1} \cdot \mathrm{s}$ ) after PAF inhalation $(P<0.02)$ to approach normal values at $45 \mathrm{~min}$, and Ps immediately decreased (by $12.9 \pm 3.1 \mathrm{mmHg})(P<0.05)$ but returned to baseline values by $8 \mathrm{~min}$ (Table III). In Fig. 2 are shown the mean \pm SEM maximum changes from baseline of the latter three variables after PAF and lyso-PAF challenges.

There were no differences in HR (PAF, $71 \pm 2$ vs lyso-PAF, $\left.75 \pm 2 \mathrm{~min}^{-1}\right), \dot{\mathrm{Q}}_{\mathrm{T}}(\mathrm{PAF}, 5.7 \pm 0.4$ vs lyso-PAF, 6.8 \pm 0.7 liter/ $\min )$, total systemic vascular resistance $\left(\mathrm{Ps} / \dot{\mathrm{Q}}_{\mathrm{T}}\right)(\mathrm{PAF}$, $16.0 \pm 1.5$ vs lyso-PAF, $14.3 \pm 1.3 \mathrm{mmHg}$ /liter per $\mathrm{min}$ ), PAP (PAF, $7.9 \pm 0.7$ vs lyso-PAF, $7.5 \pm 0.9 \mathrm{mmHg}$ ), and total pulmonary vascular resistance $\left(\mathrm{PAP} / \dot{\mathrm{Q}}_{\mathrm{T}}\right)(\mathrm{PAF}, 1.5 \pm 0.2$ vs lysoPAF, $1.1 \pm 0.2 \mathrm{mmHg} /$ liter per $\mathrm{min}$ ) between PAF and lysoPAF challenges. No increases in the respiratory fluctuation of PAP, suggestive of the generation of negative intrathoracic pressures caused by increased inspiratory airway resistance, were recorded after PAF challenge.

\section{Discussion}

Principal findings. The most novel finding of our study was that after inhaled PAF, healthy individuals with a negative methacholine challenge developed transient, sometimes striking, pulmonary gas exchange abnormalities, together with mild increases in total ventilation and the resistance of the respiratory system and a mild reduction in systemic arterial pressure. The gas exchange abnormalities were the result of increased $\dot{\mathrm{V}}_{\mathrm{A}} / \dot{\mathrm{Q}}$ inequality with resultant decrements in the $\mathrm{Pa}_{\mathrm{O}_{2}}$ and increases in the $\mathrm{AaPO}_{2}$, in a pattern similar to those commonly observed in patients with bronchial asthma but not with those shown during ARDS, in whom intrapulmonary shunting is the principal component of hypoxemia (12). Yet, the increase in Rrs was small (of the order of $35 \%$ ), at least compared to that induced in patients with mild asthma after a dose-response curve bronchial challenge with methacholine (of the order of $88 \%$ ) (10). By contrast, lyso-PAF, a substance chemically similar to PAF, albeit biologically inactive, had essentially no effect on any of the variables studied, including pulmonary gas exchange, thereby suggesting that the effects seen after PAF were not related to a nonspecific effect of inhaling a phospholipid. Overall, these results confirm our hypothesis that inhaled PAF is also capable of causing deterioration of $\dot{\mathrm{V}}_{\mathbf{A}} / \dot{\mathrm{Q}}$ relationships in healthy individuals.

Methodological concerns. We were especially concerned with ensuring that adequate steady-state conditions were reached. Because of the unknown effects of PAF on the time course of pulmonary gas exchange, we began collecting data at 2 min after challenge. However, by the criteria listed above ( see Methods), adequate steady-state conditions were achieved and maintained at each time point, even by 2 min.

Work of other investigators. To our knowledge, this is the most thorough study to investigate the pulmonary hemodynamic and gas exchange responses to PAF in healthy humans to date. Mojarad et al. (5) studied respiratory gases in a canine model of lung edema induced by PAF, but failed to show changes in the edema-induced hypoxemia. By contrast, Denjean et al. (26) demonstrated that in baboons, immediately after intratracheal administration of PAF, marked hypoxemia indirectly related to an increase in unperfused lung areas occurred. Christman and co-workers (7) demonstrated in sheep that PAF infusion increases $\mathrm{AaPO}_{2}$, at doses that cause significant changes in lung mechanics and pulmonary vascular resistance. In humans, similar results to those of Denjean et al. (26) were obtained after instilling PAF intratracheally (at a dose $\sim 100 \%$ larger than in the present study) in seven patients presenting with cerebral death while breathing $100 \%$ oxygen (27). However, they did not use MIGET to characterize $\dot{\mathrm{V}}_{\mathrm{A}} / \mathrm{Q}$ changes. PAF has been previously shown to be not only a potent systemic hypotensive agent (28), but also a pulmonary vasoconstrictor (29) or vasodilator (30), depending on the dosage and the mode of administration, the animal species studied, and the tone of the underlying vasculature. In our study, inhalation of PAF induced a slight reduction in systemic arte- 
rial pressure, while pulmonary artery pressure remained essentially unchanged. These minor hemodynamic changes are consistent with the flushing we and others have observed, suggesting that PAF or related products may act systemically after bronchial inhalation.

Interpretation of gas exchange abnormalities. It is of interest to discuss not only the magnitude but also the similarity of PAF-induced $\dot{\mathrm{V}}_{\mathrm{A}} / \dot{\mathrm{Q}}$ changes to those of natural asthma. The deterioration of $\dot{V}_{A} / \dot{Q}$ relationships resulted from an increase in the dispersion of pulmonary blood flow rather than of ventilation, because of the development of low $\dot{V}_{A} / \dot{Q}$ regions. This is qualitatively similar to what is seen in patients with bronchial asthma, of moderate (25), severe chronic (31), or the most severe life-threatening acute clinical forms $(32,33)$. That the dispersion for blood flow is more abnormal than that for ventilation is commensurate with the underlying pathophysiology of gas exchange abnormalities in patients with asthma, in whom widespread airway narrowing leads to the presence of areas that remain perfused but are poorly ventilated; i.e., areas of low $\dot{\mathrm{V}}_{\mathrm{A}} / \mathrm{Q}$ ratios. It should be noted that the $\dot{\mathrm{V}}_{\mathrm{A}} / \dot{\mathrm{Q}}$ abnormalities and reduced $\mathrm{Pa}_{\mathrm{O}_{2}}$ occurred in the face of any increase of total ventilation, which would be expected to improve both $\mathrm{Pa}_{\mathrm{O}_{2}}$ and $\dot{\mathrm{V}}_{\mathrm{A}} / \dot{\mathrm{Q}}$ relationships, other factors equal (34). The fall in $\mathrm{Pa}_{\mathrm{O}_{2}}$ caused by the deterioration of $\dot{\mathrm{V}}_{\mathrm{A}} / \mathrm{Q}$ relationships after PAF was, therefore, partly offset by the simultaneous effect of increased ventilation.

Another point of interest was the magnitude of change. In absolute terms, and examining mean data, the degree of $\dot{\mathrm{V}}_{\mathrm{A}} / \mathrm{Q}$ inequalities caused by PAF was mild to moderate. However, given that these were healthy individuals with a nonuniform response to PAF, the changes in some individuals were relatively severe (Fig. 1). By comparison, in studies designed to assess the effects of gas exchange of both exercise and simulated high altitude in young healthy men $(22,23)$, the development of $\dot{V}_{A} / \dot{Q}$ mismatch was much smaller than that seen in the present investigation. Likewise, the administration of the potent vasodilator nifedipine during hypoxia, at rest, in normal volunteers showed a very small increase in the $\dot{\mathrm{V}}_{\mathrm{A}} / \dot{\mathrm{Q}}$ dispersion (24).

Mechanism of action. The mechanism by which PAF induced $\dot{\mathrm{V}}_{\mathrm{A}} / \mathrm{Q}$ mismatching in our subjects may be related to at least two factors: bronchoconstriction and airway microvascular leakage (11). However, the possibility that the small increases in Rrs shown after PAF in the present study can also reflect changes in the viscoelastic resistance of the lung parenchyma (potentially induced by mild pulmonary edema) rather than to reduction in airway caliber, cannot be ruled out. In addition to overall airways resistance, it is considered that Rrs includes also tissue resistances of the lung and chest wall (10). Conceivably, both bronchoconstriction and airway leakage may contribute synergistically to widespread airway narrowing, hence leading to the development of areas of low $\dot{V}_{A} / \dot{Q}$ ratios.

However, we suggest that the $\dot{\mathrm{V}}_{\mathrm{A}} / \dot{\mathrm{Q}}$ inequalities seen after PAF are more related to altered airway vascular permeability rather than to bronchoconstriction and are consistent with a large body of evidence based upon three complementary findings. First, we have previously shown that inhalation of PAF in anesthesized guinea pigs induced a large degree of airway microvascular leakage, but small increases in lung resistance, compared with inhaled histamine and 5-hydroxytryptamine, which have direct contractile effect on airway smooth muscle (35).
Since airway microvascular leakage correlated significantly with changes in lung resistance, it was suggested that airway edema could be a marked component of airway narrowing induced by PAF. Airway microvascular permeability may occur by either a direct local effect of PAF on the airways (36) or, indirectly, via the activation of neutrophils (3). Although PAF may induce airway narrowing by causing airway edema in addition to airway smooth muscle contraction (18), PAF has been reported to have either no effect (37) or a modest but variable effect on the contraction of human isolated airways (38).

A second argument comes also from another study of our group on the effects of methacholine challenge on gas exchange in mild asthma (10). In that study, although methacholine (which has a primary effect on airway smooth muscle) caused, in a subgroup of seven patients with a forced expiratory volume in the first second $\left(\mathrm{FEV}_{1}\right)>90 \%$ predicted and mild $\dot{\mathrm{V}}_{\mathrm{A}} / \mathrm{Q}$ inequality (mean $\log$ SD Q, 0.67) at baseline, a $30 \%$ fall in $\mathrm{FEV}_{1}$ and a marked increase in the resistance of the respiratory system (of the order of $103 \%$ ) it induced much less $\dot{\mathrm{V}}_{\mathrm{A}} / \dot{\mathrm{Q}}$ mismatch (mean increase in $\log$ SD Q, 42\%) than in the present study. This suggests that even considerable bronchoconstriction per se does not cause necessarily much $\dot{\mathrm{V}}_{\mathrm{A}} / \mathrm{Q}$ inequality, at least acutely.

Finally, a third line of evidence comes from the study by Rubin et al. (39), which documented that inhaled PAF, at similar doses used in the present study, induced very small changes in $\mathrm{FEV}_{1}$ (of the order of $5 \%$ ) in comparison to relatively larger changes in more sensitive tests of airflow obstruction in healthy subjects; similarly, asthmatic patients showed a $10 \%$ decrease in $\mathrm{FEV}_{1}$ at the same PAF concentration. We now demonstrate similar Rrs changes in our study that indicate that PAF is not potent in inducing airway narrowing. Our data are further reinforced by a recent observation of our group that, using a similar design in another series of healthy subjects (40), inhalation of PAF caused similar changes in Rrs and in gas exchange. However, each of these arguments is indirect and, therefore, the mechanism by which PAF induces $\dot{V}_{A} / \dot{Q}$ abnormalities in humans requires more direct investigation.

Despite the lack of a significant correlation between preand post-PAF challenge changes in leucocytes and gas exchange, it is clear that there was a temporal association between the two parameters. The question arises as to whether white blood cell changes may be related directly to the mechanism of PAF-induced gas exchange abnormalities. Reversible pulmonary neutrophil sequestration within the lung after inhaled PAF has been recently shown in healthy individuals (41). In our study, we observed more leukopenia and neutropenia in arterial blood than in the mixed venous blood after PAF, possibly reflecting transient lung sequestration of neutrophils. However, it is of interest to outline that the sequestration of leucocytes in the pulmonary vasculature during hemodialysis, a condition also associated with transient hypoxemia, does not aggravate $\dot{\mathrm{V}}_{\mathrm{A}} / \mathrm{Q}$ mismatching, or induce $\mathrm{O}_{2}$ diffusion disequilibrium in humans (42) or animals (43); and if it did, one would expect the development of high $\dot{\mathrm{V}}_{\mathrm{A}} / \dot{\mathrm{Q}}$ regions, which we never saw.

In summary, we have shown that inhaled PAF in healthy volunteers has variable, occasionally marked, transient effects on pulmonary gas exchange, resulting in considerable $\dot{\mathrm{V}}_{\mathrm{A}} / \dot{\mathrm{Q}}$ mismatch in a pattern similar to that of asthma. These results support the notion that PAF may play a major role as a media- 
tor of inflammation in human airways but the importance of PAF in the pathogenesis of bronchial asthma or ARDS remains to be determined.

\section{Acknowledgments}

The authors are grateful to Cristina Santos, M.D., for her help, and to Felip Burgos, Jaume Cardús, and Conxi Gistau for their outstanding technical expertise.

Supported by Grant 91/0290 from the Fondo de Investigación Sanitaria (FIS) (Spain) and a grant from Grupo Glaxo (Spain). Dr. M. A. Félez is a postdoctoral research fellow (1992) of Hospital Clínic.

\section{References}

1. Shaw, J. O., R. N. Pinckard, K. Ferrigni, L. M. McManus, and D. J. Hanahan. 1981. Activation of human neutrophils with 1-O-hexadecyl/octadecyl-2-acetyl-sn-glyceryl-3-phosphorylcholine, the active moiety of platelet-activating factor. J. Immunol. 127:1250-1255.

2. Wardlaw, A. J., R. Moqbel, O. Cromwell, and A. B. Kay. 1986. Platelet-activating factor. A potent chemotactic and chemockinetic factor for human eosinophils. J. Clin. Invest. 78:1701-1706.

3. Evans, T. W., K. F. Chung, D. F. Rogers, and P. J. Barnes. 1987. Effect of platelet-activating factor on airway vascular permeability: possible mechanisms J. Appl. Physiol. 63:479-484.

4. Burhop, K. E., J. G. N. Garcia, W. M. Selig, S. Lo, H. Van der Zee, J. E. Kaplan, and A. B. Malik. 1986. Platelet-activating factor increases lung vascular permeability to protein. J. Appl. Physiol. 61:2210-2217.

5. Mojarad, M., Y. Hamasaki, and S. I. Said. 1983. Platelet-activating factor increases pulmonary microvascular permeability and induces pulmonary edema. A preliminary report. Bull. Eur. Physiopathol. Respir. 19:253-256.

6. Burhop, K. E., H. Van der Zee, R. Bisias, J. E. Kaplan, and A. B. Malik. 1986. Pulmonary vascular response to platelet-activating factor in awake sheep and the role of cyclooxygenase metabolites. Am. Rev. Respir. Dis. 134:548-554.

7. Christman, B. W., P. L. Lefferts, G. A. King, and J. R. Snapper. 1988. Role of circulating platelets in PAF-induced pulmonary dysfunction in awake sheep J. Appl. Physiol. 64:2033-41.

8. Cuss, F. M., C. M. S. Dixon, and P. J. Barnes. 1986. Effects of inhaled platelet activating factor on pulmonary function and bronchial responsiveness in man. Lancet. ii:189-192.

9. Wardlaw, A. J., K. F. Chung, R. Moqbel, A. Hartnell, M. McCusker, P. J. Barnes, J. V. Collins, and A. B. Kay. 1990. Effects of inhaled PAF in humans on circulating and bronchoalveolar lavage fluid neutrophils. Relationships to bronchoconstriction and airway responsiveness. Am. Rev. Respir. Dis. 141:386-392.

10. Rodriguez-Roisin, R., A. Ferrer, D. Navajas, A. G. N. Agustí, P. D. Wagner, and J. Roca. 1991. Ventilation-perfusion mismatch after methacholine challenge in patients with mild bronchial asthma. Am. Rev. Respir. Dis. 144:88 94.

11. Chung, K. F. 1992. Platelet-activating factor: an inflammatory mediator with potential contribution to respiratory diseases. Clin. Sci. 83:127-138.

12. Wagner, P. D., and R. Rodriguez-Roisin. 1991. Clinical advances in pulmonary gas exchange. Am. Rev. Respir. Dis. 143:883-888.

13. Roca, J., J. Sanchis, A. Agustí-Vidal, F. Segarra, D. Navajas, R. Rodriguez-Roisin, P. Casán, and S. Sans. 1986. Spirometric reference values for a Mediterranean population. Bull. Eur. Physiopathol. Respir. 22:217-224.

14. Wagner, P. D., H. A. Saltzman, and J. B. West. 1974. Continuous distributions of ventilation-perfusion ratios: theory. J. Appl. Physiol. 36:588-599.

15. Rodriguez-Roisin, R., J. Roca, R. Guitart, A. G. N. Agustí, A. Torres, and P. D. Wagner. 1986. Measurements of ventilation-perfusion ratios: multiple inert gas elimination technique. Rev. Esp. Fisiol. 42:258-266.

16. Rodriguez-Roisin, R., J. Roca, A. G. N. Agustí, R. Mastai, P. D. Wagner, and J. Bosch. 1987. Pulmonary vascular reactivity in patients with liver cirrhosis Am. Rev. Respir. Dis. 135:1085-1092.

17. Evans, J. W., and P. D. Wagner. 1977. Limits on $\dot{V}_{A} / \dot{Q}$ distributions from analysis of experimental inert gas elimination. J. Appl. Physiol. 42:889-898.

18. Chung, K. F., G. Dent, and P. J. Barnes. 1989. Effects of salbutamol on bronchoconstriction, bronchial hyperresponsiveness, and leucocyte responses induced by platelet activating factor in man. Thorax. 44:102-107.

19. Chung, K. F., and P. J. Barnes. 1989. Effects of platelet activating factor on airway calibre, airway responsiveness, and circulating cells in asthmatic subjects. Thorax. 44:108-115.

20. Wagner, P. D., and J. B. West. 1980. Ventilation-perfusion relationships. In Pulmonary Gas Exchange. Volume I: Ventilation, blood flow, and diffusion.

J. B. West, editor. Academic Press, New York. pp. 219-262.

21. Matthews, J. N. S., D. F. Altman, M. J. Campbell, and P. Royston. 1990. Analysis of serial measurements in medical research. Br. Med. J. 300:230-235.

22. Gale, G. R., J. R. Torre-Bueno, R. E. Moon, H. A. Saltzman, and P. D. Wagner. 1985. Ventilation-perfusion inequality in normal humans during exercise at sea level and simulated altitude. J. Appl. Physiol. 58:978-988.

23. Wagner, P. D., G. E. Gale, R. E. Moon, J. R. Torre-Bueno, B. W. Stolp, and H. A. Saltzman. 1986. Pulmonary gas exchange in human exercising at sea level and simulated altitude. J. Appl. Physiol. 61:260-270.

24. Mélot, C., R. Naeije, R. Hallemans, P. H. Lejeune, and P. Mols. 1987. Hypoxic pulmonary vasoconstriction and pulmonary gas exchange in normal man. Respir. Physiol. 68:11-27.

25. Wagner, P. D., G. Hedenstierna, and G. Bylin. 1987. Ventilation-perfusion inequality in chronic asthma. Am. Rev. Respir. Dis. 136:605-612.

26. Denjean, A., B. Arnoux, R. Masse, A. Lockhart, and J. Benveniste. 1983. Acute effects of intratracheal administration of platelet-activating factor in baboons. J. Appl. Physiol. 55:799-804.

27. Gateau, O., B. Arnoux, H. Deriaz, P. Viars, and J. Benveniste. 1984. Acute effects of intratracheal administration of PAF-acether (platelet-activating factor) in humans. Am. Rev. Respir. Dis. 129(Part 2):A3. (Abstr.)

28. Halonen, M., J. D. Palmer, I. C. Lohman, L. M. McManus, and R. N. Pinckard. 1980. Respiratory and circulatory alterations induced by acetyl glyceryl ether phosphorylcoline, a mediator of IgE anaphylaxis in the rabbit. Am. Rev. Respir. Dis. 122:915-924.

29. Laurindo, F. R. M., R. E. Goldstein, N. J. Davenport, D. Ezra, and G. Z. Feuerstein. 1989. Mechanisms of hypotension produced by platelet-activating factor. J. Appl. Physiol. 66:2681-2689.

30. Mcmurtry, I. F., and K. G. Morris. 1986. Platelet-activating factor causes pulmonary vasodilation in the rat. Am. Rev. Respir. Dis. 134:757-762.

31. Ballester, E., J. Roca, L. I. Ramis, P. D. Wagner, and R. Rodriguez-Roisin. 1990. Pulmonary gas exchange in severe chronic asthma. Response to $100 \%$ oxygen and salbutamol. Am. Rev. Respir. Dis. 141:558-562.

32. Roca, J., L. I. Ramis, R. Rodriguez-Roisin, E. Ballester, J. M. Montserrat, and P. D. Wagner. 1988. Serial relationships between $\dot{V}_{A} / Q$ inequality and spirometry in acute severe asthma requiring hospitalization. Am. Rev. Respir. Dis. 137:605-612.

33. Rodriguez-Roisin, R., E. Ballester, J. Roca, A. Torres, and P. D. Wagner. 1989. Mechanisms of hypoxemia in patients with status asthmaticus requiring mechanical ventilation. Am. Rev. Respir. Dis. 139:732-739.

34. Rodriguez-Roisin, R., and P. D. Wagner. 1989. Clinical relevance of ventilation-perfusion inequality determined by inert gas elimination. Eur. Respir. J. 3:469-82.

35. Tokuyama, K., J. O. Lötvall, P. J. Barnes, and K. F. Chung. 1991. Mechanism of airway narrowing caused by inhaled platelet-activating factor. Role of airway microvascular leakage. Am. Rev. Respir. Dis. 143:1345-1349.

36. Humphrey, D. M., L. M. McManus, D. J. Hanahan, and R. N. Pinckard. 1984. Morphologic basis of increased vascular permeability induced by acetyl glyceryl ether phosphorylcholine. Lab. Invest. 50:16-25.

37. Schellenberg, R. R. 1987. Airway responses to platelet-activating factor. Am. Rev. Respir. Dis. 136:S28-S32.

38. Johnson, P. R. A., J. L. Black, and C. L. Armour. 1992. Platelet-activating factor-induced contraction of human isolated bronchus. Eur. Respir. J. 5:970974.

39. Rubin, A. E., L. J. Smith, and R. Patterson. 1987. The bronchoconstrictor properties of platelet-activating factor in humans. Am. Rev. Respir. Dis. 136:1145-1151

40. Félez, M. A., J. A. Barberà, J. Roca, C. Santos, M. M. Rotger, K. F. Chung, D. Navajas, and R. Rodriguez-Roisin. 1992. Salbutamol inhibits pulmonary effects of inhaled platelet-activating factor in man. Eur. Respir. J. 5(Suppl. 15):273S. (Abstr.)

41. Tam, F. W. K., J. Clague, C. M. S. Dixon, A. W. J. Stuttle, B. L. Henderson, A. M. Peters, J. P. Lavender, and P. W. Ind. 1992. Inhaled platelet-activating factor causes pulmonary neutrophil sequestration in normal humans. Am. Rev. Respir. Dis. 146:1003-1008.

42. Romaldini, H., R. Rodriguez-Roisin, F. A. Lopez, T. W. Ziegler, H. Z. Bencowitz, and P. D. Wagner. 1984. The mechanisms of arterial hypoxemia during hemodialysis. Am. Rev. Respir. Dis. 129:780-784.

43. Ralph, D. D., S. M. Ott, D. J. Sherrard, and M. P. Hlastala. 1984. Inert gas analysis of ventilation-perfusion matching during hemodialysis. J. Clin. Invest. 73:1385-1391. 